\title{
HOW TO PINPOINT ENERGY-INEFFICIENT BUILDINGS? AN APPROACH BASED ON THE 3D CITY MODEL OF VIENNA
}

\author{
B. Skarbal ${ }^{\text {a }}$, J. Peters-Anders ${ }^{\text {a }}$, A. Faizan Malik ${ }^{\text {b }}$, G. Agugiaro ${ }^{\text {a, * }}$ \\ ${ }^{a}$ Austrian Institute of Technology, Smart Citites and Regions Research Field, Giefinggasse 2, 1210 Vienna, Austria \\ \{bernhard.skarbal, jan.peters-anders, giorgio.agugiaro\}@ait.ac.at \\ ${ }^{\mathrm{b}}$ Vienna University of Economics and Business, Institute for Economic Geography and GIScienceInstitute (WU Wien), \\ Welthandelsplatz 1, 1020 Vienna, Austria \\ malik.faizan.ahmed@s.wu.ac.at
}

Commission IV, WG IV/10

KEY WORDS: CityGML, 3D city modelling, Urban Energy Modelling, 3D Visualisation, Energy Performance of Buildings

\begin{abstract}
:
This paper describes a methodology to assess the energy performance of residential buildings starting from the semantic 3D city model of Vienna. Space heating, domestic hot water and electricity demand are taken into account.

The paper deals with aspects related to urban data modelling, with particular attention to the energy-related topics, and with issues related to interactive data exploration/visualisation and management from a plugin-free web-browser, e.g. based on Cesium, a WebGL virtual globe and map engine.

While providing references to existing previous works, only some general and introductory information is given about the data collection, harmonisation and integration process necessary to create the CityGML-based 3D city model, which serves as the central information hub for the different applications developed and described more in detail in this paper.

The work aims, among the rest, at developing urban decision making and operational optimisation software tools to minimise nonrenewable energy use in cities.

The results obtained so far, as well as some comments about their quality and limitations, are presented, together with the discussion regarding the next steps and some planned improvements.
\end{abstract}

\section{INTRODUCTION}

Cities are confronted today with a number of challenges due, on one hand, to the global phenomenon of growing urbanisation and, on the other hand, to the continuously increasing demand of resources required, for example, by higher living standards. To this extent, energy is one of the most crucial resources cities need to deal with, and at city level there is a general struggle nowadays to increase the overall efficiency, reduce the energy consumption per capita, and as a direct consequence, the emissions of $\mathrm{CO}_{2}$ and other greenhouse gases.

The European Union, for example, is aiming for a $27 \%$ cut in Europe's annual primary energy consumption by 2030 . Some measures to reduce the energy consumption focus particularly on the building sector, as buildings alone consume circa $40 \%$ of the total energy, of which about $68 \%$ is used by households, mainly for space heating, cooling, domestic hot water preparation, cooking and appliances.

Urban energy planning is however a difficult task, as it needs to find answers to a number of complex questions. At building level, for example, some open questions are a) where are inefficient buildings? b) how to increase their efficiency (e.g. by refurbishment) c) how to evaluate the impact of these measures? However, changing the scale from the single building to the block/district and up to the city level, a number of other questions arise, such as: d) how to evaluate the energy performance of a block or a district? e) how is the energy demand going to change in the near and mid-term future in a block or district? f) what is going to happen to current and future energy distribution networks as the energy demand changes over time?
Answering these questions requires a deep understanding of the complex system interdependencies at urban level, as it plays a crucial role to have a comprehensive knowledge of the demand and supply of energy resources, including their (multi-scale) spatial characteristics and distribution within urban areas.

This is indeed one of the goals of the European Marie-Curie ITN project "CI-NERGY, Smart cities with sustainable energy systems" [CI-NERGY], which aims, among the rest, at developing urban decision making and operational optimisation software tools to minimise non-renewable energy use in cities. As case studies, the project involves the municipalities of Geneva and Vienna, which were chosen for their very ambitious sustainability goals. Although this paper focuses on Vienna, CINERGY-related information about the other case study city Geneva can be found in (Agugiaro et al. 2017), also published in the proceedings of this conference.

In Vienna, the adoption in 2014 of the Smart City Wien framework strategy [SC-W], which builds upon and extends the previous Urban Energy Efficiency Programme [SEP-W], represents a great step towards sustainable energy supply through resource conservation and intelligent use of resources. The strategy defines energy-relevant targets for different areas, such as efficient energy use, renewable energy sources, infrastructure, mobility, and buildings. One of the overall goals is to decrease the final energy consumption per capita in Vienna by $40 \%$ by 2050 (compared to 2005) and, at the same time, the per-capita primary energy input should drop from 3000 to 2000 Watt, i.e. to $48 \mathrm{kWh}$ per day, as envisioned by the so-called 2000-W-society.

More specifically, on the building sector comprehensive refurbishment activities are planned to reduce the energy

\footnotetext{
* Corresponding author
} 
consumption of existing buildings for space heating, cooling and domestic hot water preparation by one percent per capita and year. This is coupled with cost-optimised zero-energy building standards for all new structures, additions and refurbishments from 2018/2020 and further development of heat supply systems.

The relevance of the above mentioned goals can be better understood if one considers the following figures regarding the building stock in Vienna: in 2011 there were approximately 165000 buildings in Vienna, of which 149000 were of residential type, while the rest served for service, industrial/commercial or other purposes. Due to demographic change and the related population growth, it is estimated that approximately 120000 new dwellings will have to be constructed by 2025 .

This paper describes a methodology to estimate the energy performance of residential buildings starting from a semantic 3D city model. Once the estimation is carried out, the most energy-inefficient buildings can be spatially identified, and a number of refurbishment scenarios can be computed depending on the data available about the specific building and the energy resources (e.g. photovoltaic, geothermal, etc.) The adoption of a $3 \mathrm{D}$ visualisation interface, as well as the possibility to query data and results at building level directly in the web-based 3D environment greatly improve the effectiveness in exploring, communicating, and (optionally) publishing the results.

The adoption of semantic 3D city models as an information hub for different application domains is relatively new in the GIS community, one of the reasons being the steady but "slow" development of proper IT tools (standard data models, database and editing tools, etc.). Nevertheless, a number of applications already exist and range from urban planning, noise mapping, augmented reality, utility network management to energy simulation tools. When it comes to energy, Carrión et al. (2010) and Strzalka et al. (2011) have proposed algorithms to estimate space heating energy demand of buildings. A city-wide energy atlas, focussing on energy demand for residential buildings, was created within the project "Energy Atlas Berlin" (Krüger and Kolbe, 2012; Kaden and Kolbe, 2013). Other conceptually similar examples exist for the cities of Stuttgart, Hamburg, Karlsruhe, Ludwigsburg in Germany, Lyon in France, Rotterdam in the Netherlands, and Trento in Italy (Nouvel et al., 2013; Bahu et al., 2013; Nouvel et al., 2015b; Agugiaro, 2016a). Given the growing relevance of the topic, several research groups are focussing on a number of different topics: for example, Molien et al. (2017) compare building modelling assumptions and methods for urban-scale heat-demand forecasting, Romero Rodríguez et al. (2017) focus on the assessment of the photovoltaic potential at urban level based on 3D city models, while Biljecki et al. (2017) deal with the generation of 3D city models without elevation data. For more information, a state-of-the-art and up-to-date review of different applications of 3D city models, including energy, can be found in Biljecki et al. (2015).

In the case of Austria, and to the authors' knowledge, there are however no other examples of adoption of a semantic 3D city model for energy-related applications other than the one described in this - and previous, however tightly related papers regarding Vienna (Agugiaro, 2016b; Agugiaro, 2016c). If, on one hand, the computation of the energy demand is conceptually comparable to the existing approaches mentioned above, this paper nevertheless also presents some data visualisation and exploration tools and describes work carried out to extend otherwise out-of-the-box missing functionalities. The paper is structured as follows: section 2 briefly describes the test area, the data sources, and the 3D model used in this work, section 3 focuses on the implemented algorithms to compute the energy demand of the residential buildings, section 4 deals with web-based 3D visualisation, data exploration and management, and section 5 contains the conclusions and the discussion regarding the next steps and some planned improvements.

\section{TEST AREA AND DATA SOURCES}

\subsection{Test area}

The $12^{\text {th }}$ district of Vienna (Meidling) was chosen as test area thanks to its heterogeneity in shape, structure and characteristics (Figure 1). Meidling spans an area of approximately $8.2 \mathrm{~km}^{2}$ and it lies just 5-7 km southwest of the city centre. Counting circa 90000 inhabitants (i.e. circa 11000 inhabitants $/ \mathrm{km}^{2}$ ), it is a heavily populated urban area with many residential buildings of greatly varying size and typology, but also with large recreational areas and parks. It can be approximately divided into two main parts: the north-eastern one is characterised by a heavily developed urban residential texture, while the southwestern one is a more mixed (industrial and light residential) area, which then gradually continues southwards. In Meidling there are circa 7400 buildings, of which approximately 5600 are residential or mixed-residential ones.

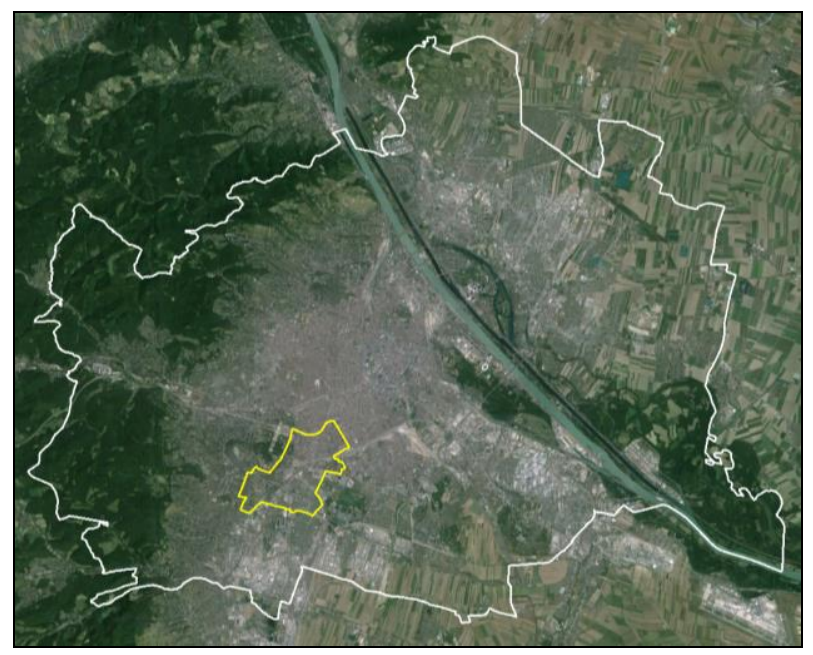

Figure 1. Boundaries of Vienna (in white) and extents of the district of Meidling (in yellow). Image source: Google Earth

\subsection{The 3D city model}

Starting from 2015, a large number of datasets (both spatial and non-spatial) were collected for the whole city of Vienna, mainly from the already available Open Government Data Wien catalogue [OGD-W], or were provided by the Municipality of Vienna for the purposes of the CI-NERGY project.

Many of them were harmonised and integrated in order to generate the semantic 3D city model according to the CityGML Open Geospatial Consortium's [OGC] standard. However, giving a detailed description of all the steps required to obtain the 3D city model is far beyond the scope of this paper. Further details can be found in Agugiaro (2016b) about the most relevant data integration issues, and in Agugiaro (2016c) regarding the extension of the CityGML data model by means of the Energy Application Domain Extension (ADE), in order to specifically enhance and extend the urban data model to accommodate energy-specific data. Further information about 
the CityGML Energy ADE can be found in Nouvel et al. (2015a) or in Benner et al. (2016) [ENERGY-ADE].

What follows is a short description of the main characteristics of the 3D city model, the data it contains, both in terms of geometries and "normal" attributes.

The 3D city model contains buildings modelled in LoD0, LoD1 and LoD2. Buildings are modelled either as multi-part objects, i.e. as a composition of CityGML BuildingParts, or as simple single-part objects. For some buildings, architectonical elements like "flying roofs" are added as Building Installations in LoD2. With the 3D city model, following attributes are available for each building:

- Name and address(es) of the building

- Building class, function and usage;

- Year of construction;

- Number of storeys above and below ground;

- Roof type;

- Building height.

Thanks to the Energy ADE, numerous other attributes and features were integrated into the 3D city model, such as:

- Gross volume (both for LoD1 and LoD2 geometries);

- Footprint area;

- Lowest rain gutter height, ridge height of the roof;

- Presence and type (conditioned or not) of the attic floor;

- Sum of all net floor areas, and building usages according to the Vienna buildings' database (AGWR, Adress-, Gebäudeund Wohnungsregister);

- Presence and characteristics of installed thermal and solar panels;

- Monthly and yearly values of global solar irradiance on the roof surfaces, and the corresponding values in terms of potential yield for photovoltaic and solar panel installations;

- Suitability of the roof surfaces for installation of solar systems;

- Classification of the residential buildings into four typologies: single-family house, terraced house, multi- family house, and apartment block (e.g. as commonly used in the project Tabula [TABULA];

- Information about the type of energy supply (gas, district heating, other, unknown).

Due to the strong heterogeneity of the input data in terms of completeness and accuracy, a series of automatic, semiautomatic and manual checks (the latter only in the area in Meidling) were carried out to reduce gross errors and further increase the overall data quality.

Moreover, in order to facilitate data exploration and analysis, all datasets were imported into a PostgreSQL 9.4 database with the PostGIS 2.2 extension. For the CityGML 3D city model, the free and open source 3DCityDB implementation for PostgreSQL was adopted [3DCityDB]. As a consequence, all data are stored in the same spatially enabled database, either as CityGML-compliant data, or as "normal" database tables.

For visualisation purposes, the 3D city model is available both for Google Earth in kmz format (Figure 2), and for the Cesiumbased 3DCityDB-Webmap-Client (Figure 3).

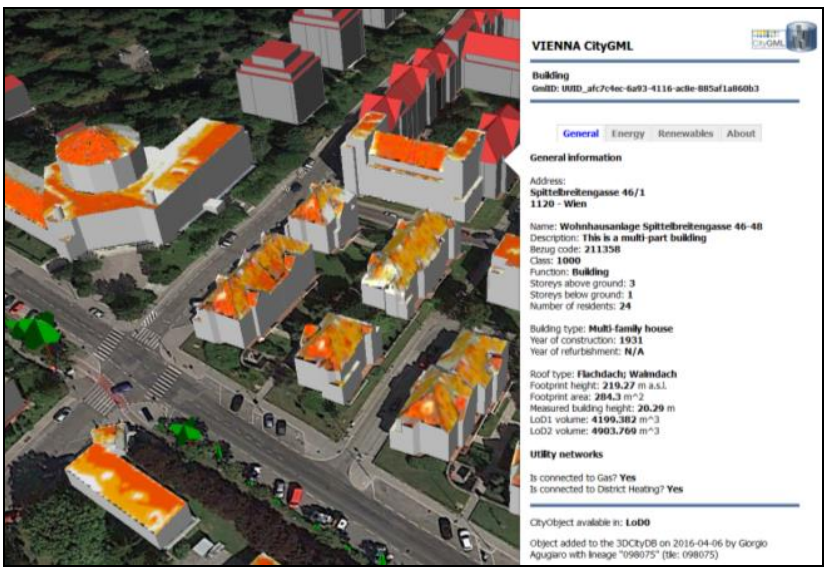

Figure 2. Example of visualisation of the $3 \mathrm{D}$ city model in Google Earth: thematic data for each building can be accessed in the balloon

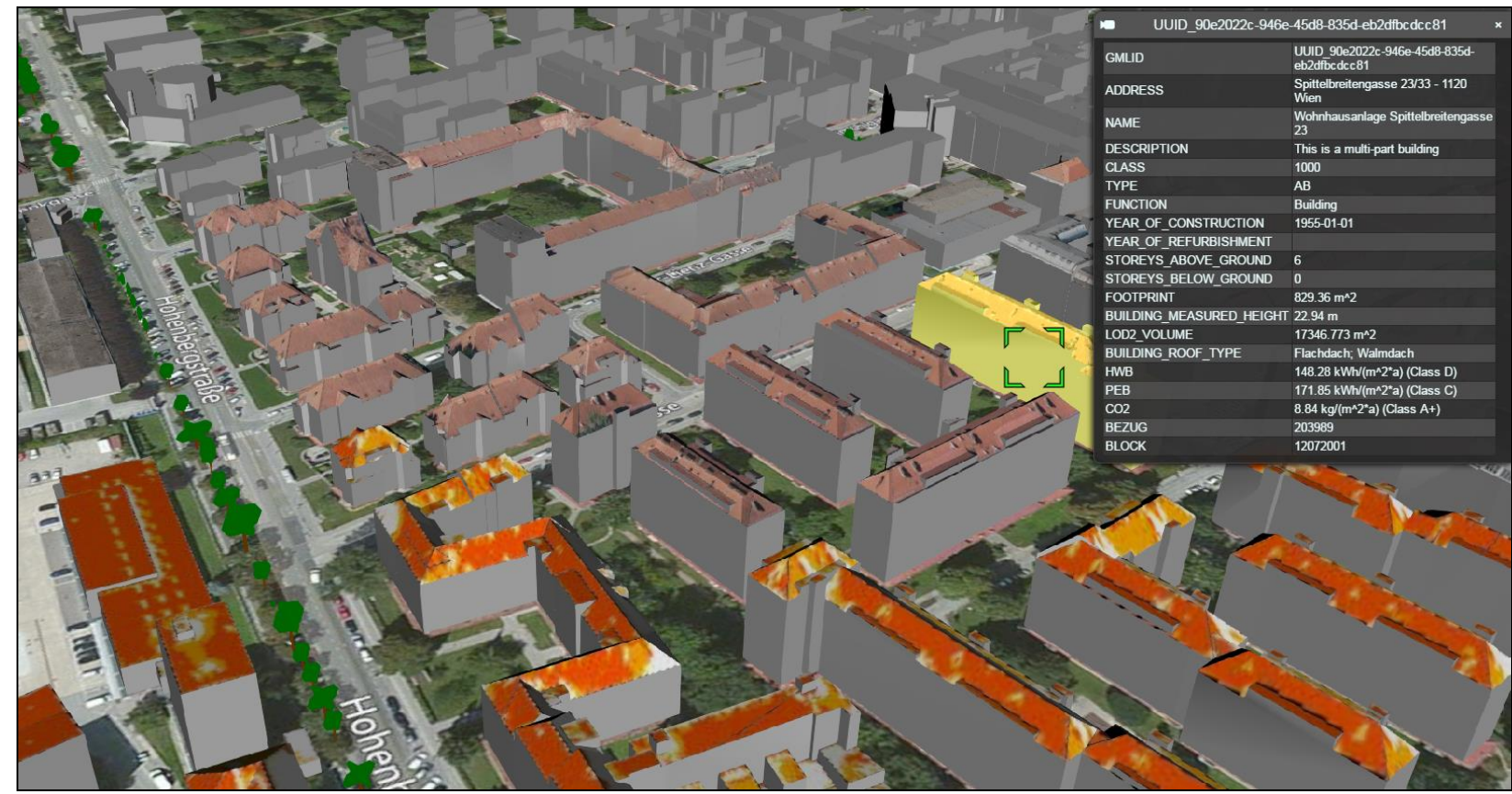

Figure 3. Example of web-based 3D visualisation of the 3D city model in Cesium. Thematic data for each building is retrieved by clicking on it 


\section{COMPUTATION OF ENERGY DEMAND FOR RESIDENTIAL BUILDINGS}

In order to compute the energy demand, all buildings had to be characterised by more specific attributes. For each building, the surface area, the azimuth and the inclination angles of the wall, ground and roof surfaces were calculated. The azimuth angles were then classified in the eight main and secondary cardinal directions (N, S, W, E, NE, NW, SE, SW). All shared walls between adjacent buildings were identified, calculated and classified. For each polygon resulting from the 3D intersection, the area was calculated and an assignment to adiabatic or nonadiabatic class was performed. Due to the Energy ADE, all the calculated geometries could be added to the 3D city model as ThermalBoundary objects and saved with the model. In addition, all buildings were classified according to their year of construction. For all residential buildings, the classification was further used to characterize them by physical parameters (e.g. $\mathrm{U}$ - and g-values) taken from existing parameter libraries, including the guideline 6 on energy performance behaviour of buildings from the Austrian Institute of Construction Engineering [OIB]. It should be mentioned here that in this work all buildings with a net floor area equal to or greater than $60 \%$ of the total net floor area of the building were treated as residential buildings. Non-residential buildings were not included in the following steps.

After all residential buildings were characterized with the necessary attributes, the heating energy demand was calculated. The heating energy demand is the most common energy characteristic and describes the amount of heat that must be supplied to the conditioned rooms in order to maintain their predetermined set temperature. The basis of the calculations was the Austrian norm ÖNORM B 8110-6. In addition to the available data from the CityGML model, further assumptions were, which are explained in the following.

- The climatic data were used in accordance with the Austrian norm ÖNORM B 8110-5. The test area Meidling is located in the moderate climatic zone North Region $(\mathrm{N})$. The assumed sea level is $156.68 \mathrm{~m}$, which is equivalent to the lowest sea level of Vienna. The assumed heating season for this region ranges from October to April;

- Due to the lack of detailed information about the internal structure, each building was modelled as a single thermal zone, with the usage profile for residential buildings according to ÖNORM B 8110-5;

- Due to the lack of explicit geometric information about the windows in the LoD2 model, a heuristic window-to-wall ratio of $28 \%$ for the outer facades was assumed to calculate the glazed surface area of the outer facade;

- The gross floor area of the buildings as a reference area for the calculation of the specific heating energy demand in $\mathrm{kWh} /\left(\mathrm{m}^{2} \cdot \mathrm{a}\right)$ was determined in two different ways:

Directly through the net floor area according to AGWR and conversion to the gross floor area by the factor 1.25;

Estimation of the gross floor area using the LoD2 gross volume and an estimated average storey height of $3.5 \mathrm{~m}$ in reference to Bretschneider et al. (2002).

While the heating energy demand provides information on the thermal quality of a building, the type of energy supply and user behaviour must also be taken into account when determining the final energy demand that needs to be delivered to the building.

For the majority of the buildings, information about whether they are heated with natural gas or district heating is known. For the remaining residential buildings, a supply of natural gas is assumed in a first approach. Starting from the heating demand and the heat demand for domestic hot water (DHW) production, the respective final energy requirement values were determined by means of the energy expenditure numbers differentiated according to energy carriers. Taking into account the household electricity demand, the primary energy demand (non-renewable, renewable, total), as well as the $\mathrm{CO}_{2}$ emissions resulting from the energy input were calculated using the primary energy factors and $\mathrm{CO}_{2}$ emission factors for each energy carrier according to the guideline 6 on energy saving and heat insulation of buildings from the Austrian Institute of Construction Engineering. The energy-related results are not only available as a year sum but also as monthly values. This allows for the presentation of the energy values over the course of the year and a differentiation into the winter season (showing the effect of the building envelope refurbishment and the low yield through photovoltaics and solar thermal energy) and the summer season (high supply of renewables by photovoltaics and solar thermal energy) as well as the comparison of demand and decentralized generation (e.g. coverage of DHW demand by solar thermal energy over the summer months) and the resulting reduction in $\mathrm{CO}_{2}$ emissions.

Using this approach, four other scenarios were calculated in addition to the baseline scenario (status quo). The scenarios deal with the refurbishment of the building envelope, increase of renewables (e.g. by photovoltaics, solar thermal energy), as well as mixed forms (refurbishment of the building envelope in combination with roof-mounted photovoltaics). In order to use economically viable solar-thermal systems for the scenario, an annual solar coverage of $50-60 \%$ for domestic hot water in single family homes and $30-40 \%$ in residential buildings was used, with up to $100 \%$ coverage of the hot water demand in summer. For the photovoltaic scenario, the appropriate roof areas were taken into account according to the solar cadastre.

Moreover, results at building level were aggregated at building block level, in order to offer a generalised view of the overall energy performance of a block.

Examples of different visualisation techniques to explore the results are presented in the following figures (Figure 4 to Figure 7). Please refer to section 4 for more details about the different visualisation tools.

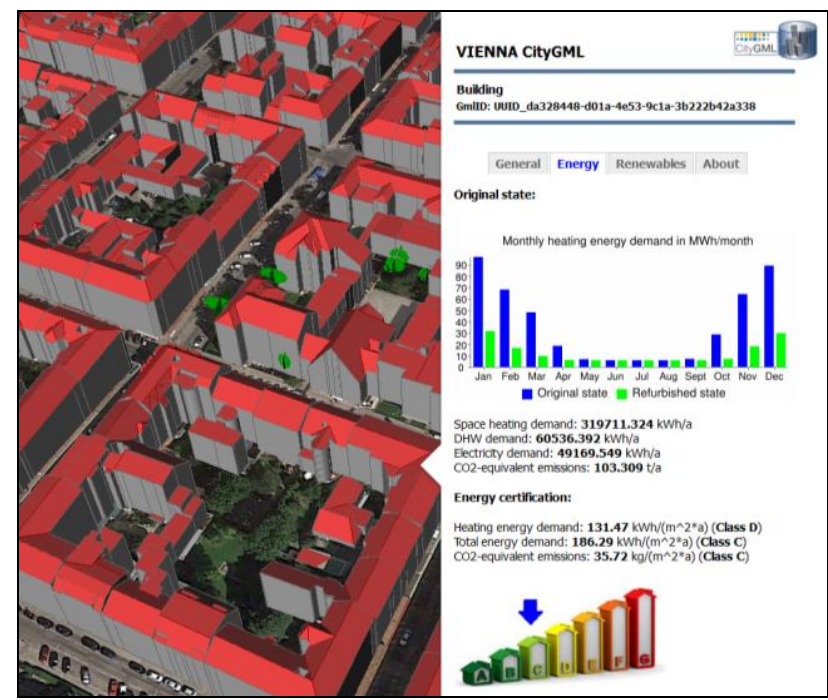

Figure 4. The Google Earth balloon contains information about the monthly heating energy demand for the original state and a refurbishment scenario, as well as data about energy demand for space heating, domestic hot water (DHW) production, $\mathrm{CO}_{2}$ emissions, and the corresponding energy performance class 

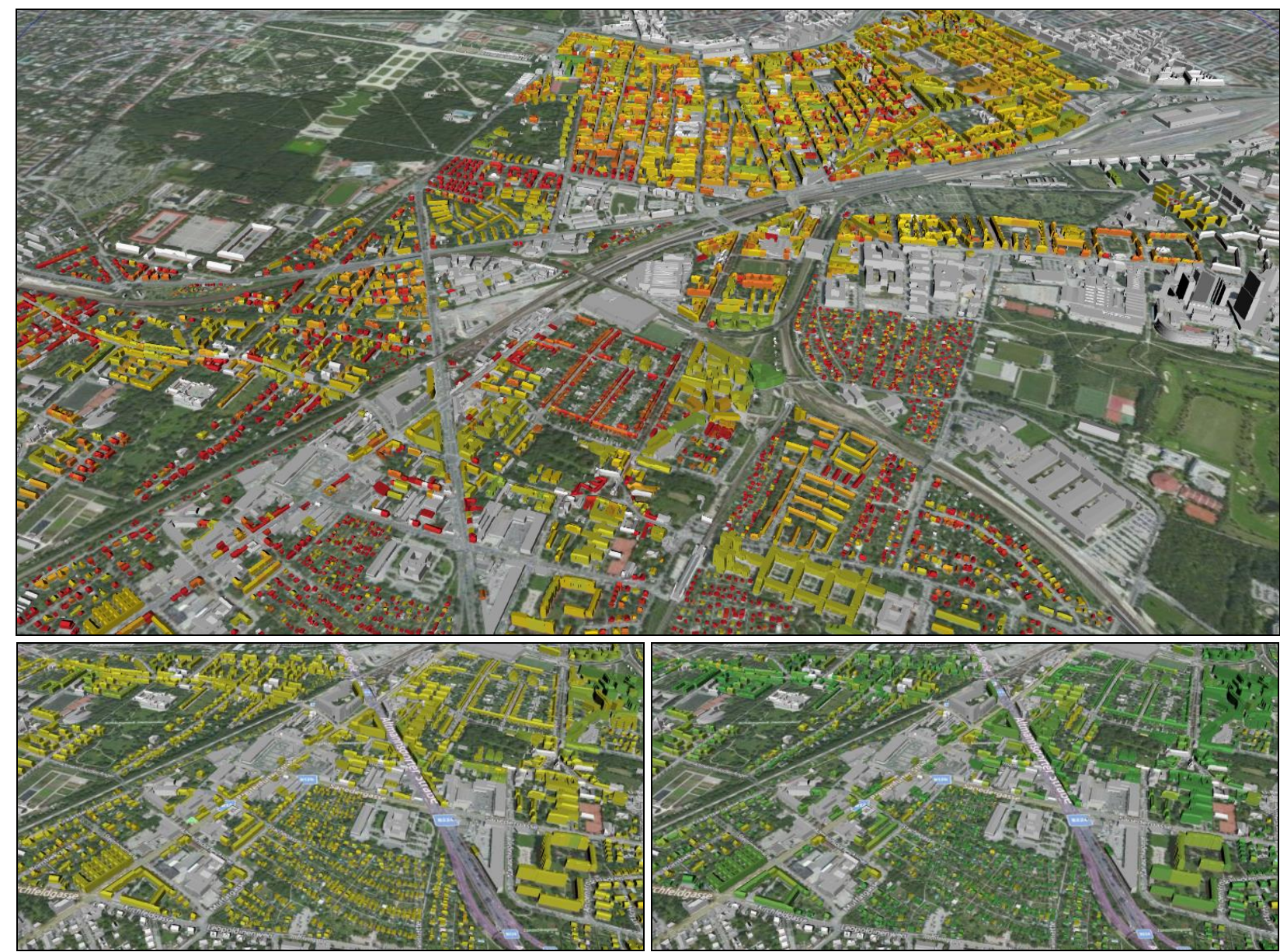

Figure 5. [Top] 3D visualisation of the energy performance class (in terms of annual area-specific primary energy demand) of all residential buildings in the $12^{\text {th }}$ district of Vienna (baseline scenario). The colours correspond to the classes provided for in the Guideline 6 of the Austrian Institute of Construction Engineering. Buildings in grey are not residential. [Bottom] Detail view of areaspecific primary energy demand in two refurbishment scenarios. Left: Scenario 1 - thermal insulation of the building envelope. Right: Scenario 2 - thermal insulation of the building envelope in combination with roof-mounted photovoltaics

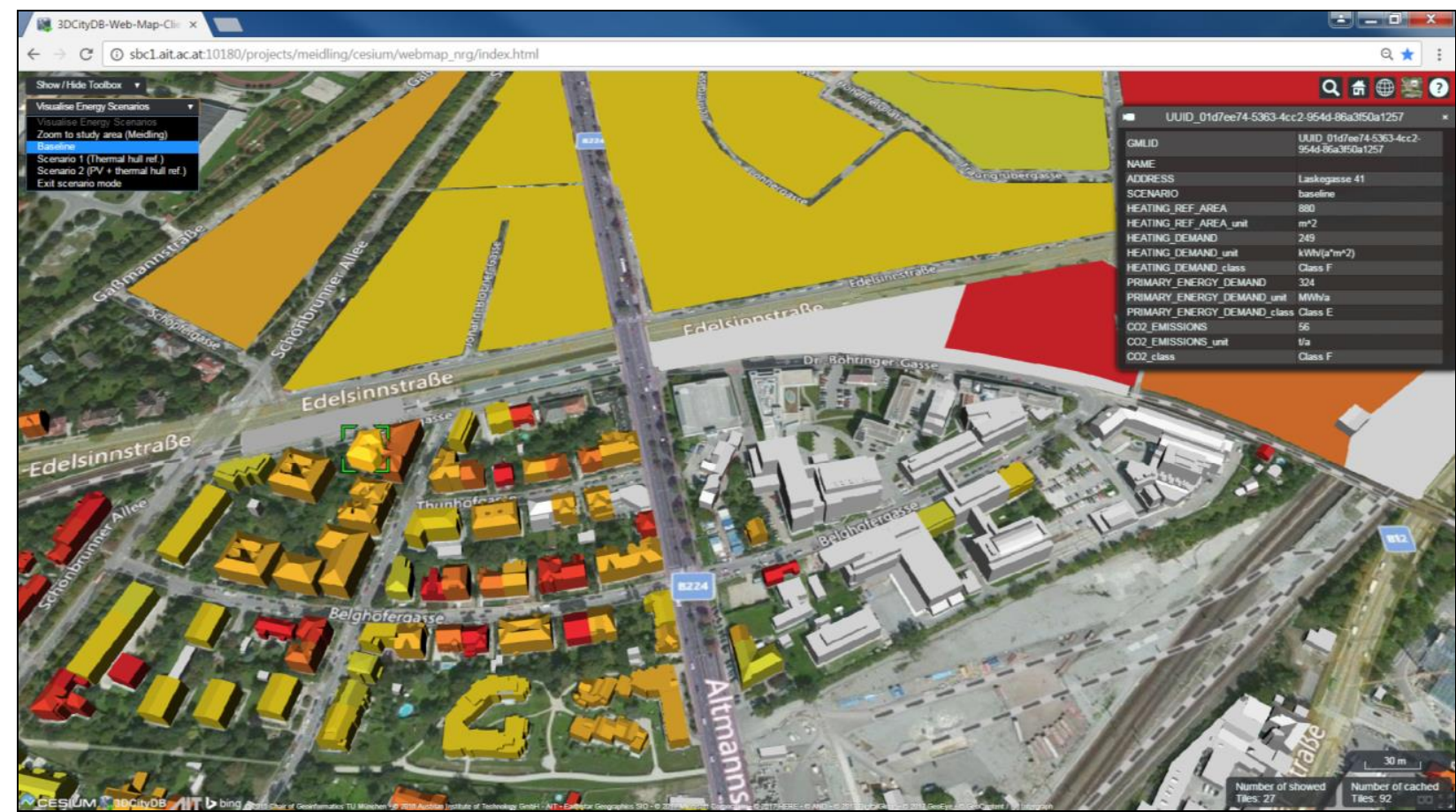

Figure 6. Example of hybrid (multi-scale) representation of the energy performance class of buildings and building blocks. The user can select among different scenarios in the upper-left drop-down menu and query buildings and blocks for thematic data 


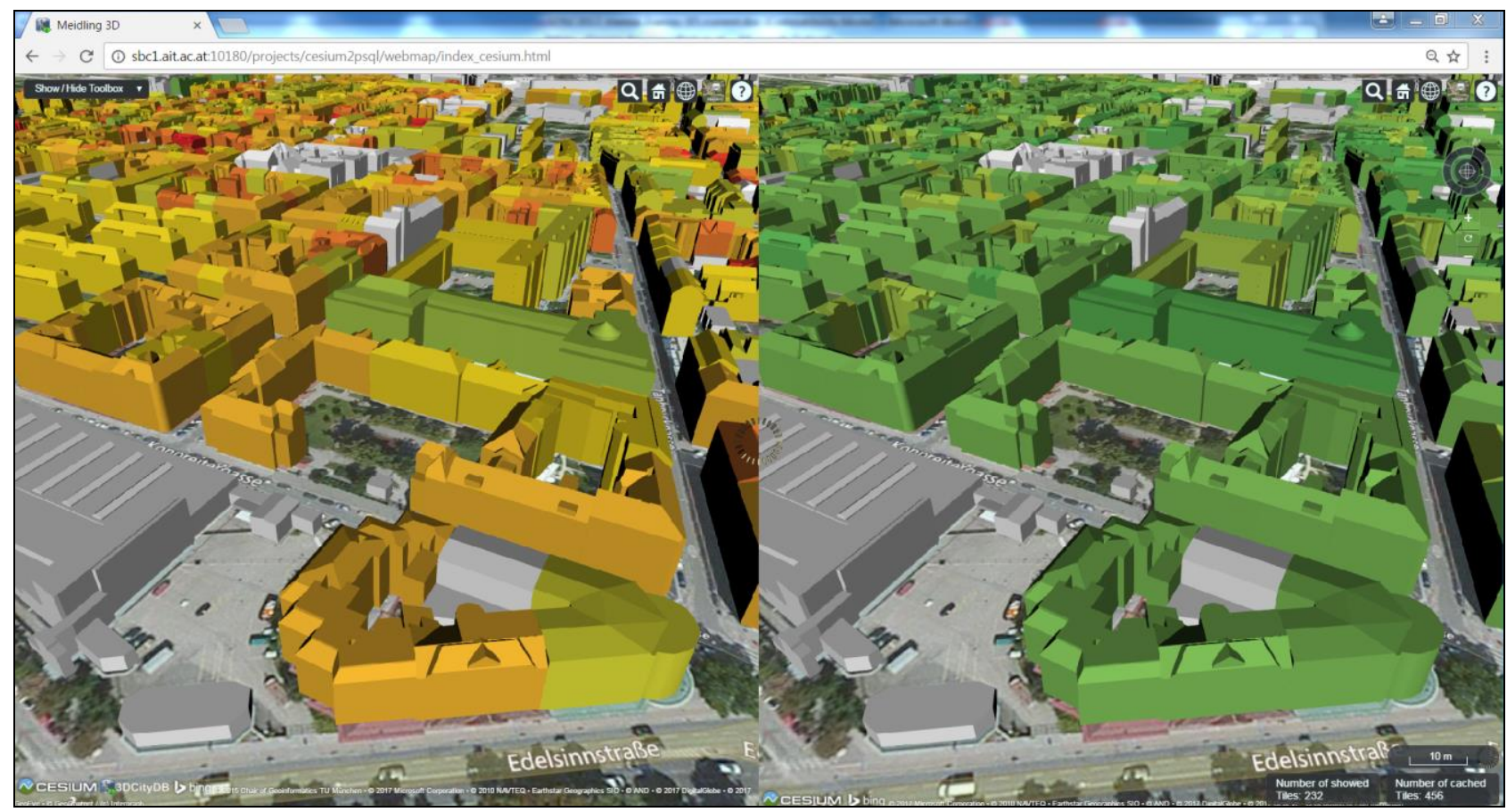

Figure 7. "Twin view" visualisation modus for energy performance scenarios: the current energy performance class of each building [left] can be compared with the corresponding one after a refurbishment has been carried out [right]

\section{WEB-BASED 3D VISUALISATION AND DATA MANAGEMENT}

In order to visualise the 3D model and the energy-related results via web, the free and open-source 3DCityDB-Webmap-Client has been used and partly extended.

The 3DCityDB-Webmap-Client acts as a front-end of the 3DCityDB for high-performance visualization and interactive exploration of semantic 3D city models in CityGML. It extends Cesium, a WebGL virtual globe and map engine [CESIUM], as visualisation engine, which is based on HTML5 and Web Graphics Library (WebGL) to provide hardware acceleration and cross-platform, plugin-free 3D visualisation functionalities. For example, different LoDs can be tiled and visualised efficiently and simultaneously, as shown in Figure 3, where the LoD1 geometries are in the background, and the LoD2 ones in the foreground with different textures: roof textures and roofsuitability for installation of solar panels. What is more, a userfriendly GUI allows to add and remove data layers of different origin (KML/glTF layers, WMS imagery layers, and Cesium digital terrain models), and the 3D visualization models in $\mathrm{KML} / \mathrm{glTF}$ (e.g. the buildings) can be linked with the cloudbased Google Fusion table allowing for querying the thematic data of every 3D object. Further details about many other features can be found in (Chaturvedi et al., 2015) and on the website [3DCITYDB-WEBMAPCLIENT].

\subsection{Visualisation of scenarios}

In order to enable and facilitate visualisation of the energyrelated results, and, most importantly, to allow for a simple and immediate comparison between different scenarios, two approaches are followed.

In the first, the user can explore the 3D model and choose between scenarios by means of a drop down menu. Energy performance classes of both buildings and blocks can be visualised at the same time, depending on the zoom settings the user decides to define. An example is presented in Figure 6.
A second approach consists in a so-called "Twin view"-modus, which enables a side-by-side visualisation of two different web client instances. It features a synchronous navigation via the master display on the left hand side and enables the user to load additional GLTF/GLB layers for further comparison. The "Twin view"-extension is still under development with further functionalities planned to be added in the near future. An example is shown in Figure 7.

\subsection{Direct connection to the PostgreSQL database}

Regarding thematic data retrieval, the 3DCityDB-WebmapClient allows only read-only access to a Google Fusion table. In order to enable both read and write access to the underlying data of the 3D model a 3DCityDB-Webmap-Client extension is also being developed allowing for querying and editing data stored in a PostgreSQL database. The extension is code-named "Cesium2PSQL" and is meant to improve data retrieval by removing the now existing middleware communication layers (i.e. Google Fusion table, Online Spreadsheets). The new interface is able to communicate in a bidirectional way in order to edit the city object attributes and write them back into the database. This enables the users to edit and update the thematic data like the year of construction, the number of storeys, etc., in order to correct errors or to entry new values.

The communication interface interacts directly with the PostgreSQL database and retrieves data depending on the requested query and the selected city object. Among the others, this approach allows to overcome a number of potential dataprivacy issues, for example when exporting data to a Google Fusion table might not be possible due to privacy reasons or relevance of the data, as Google Fusion is a web service publicly available and not well suited for privacy-sensible data. The communication interface extends the 3DCityDB-WebmapClient's functions: it loads the data dynamically on each request from the PostgreSQL database and returns the response in JSON (JavaScript Object Notation) format for visualisation, data exploration, and analysis. The interface uses a REST 
(Representational State Transfer) architecture that is also known as RESTful APIs (Application Programming Interfaces). Whenever the user clicks on a city object within the 3DCityDBWebmap-Client's map, the request is sent to the REST APIs server and the requested action is performed. The REST APIs server is connected to the PostgreSQL database and retrieves the selected city object's attributes (in case the request is a HTTP GET request), or updates the city object attributes (in case the request is HTTP POST request). The server then sends the response of each request, including all the attributes' information of the city object and the status code as a JSON response. On the client side, the 3DCityDB-Webmap-Client parses the response and populates the city object attributes information along with their attribute names. The following Figure 8 depicts the architecture of the REST APIs server.

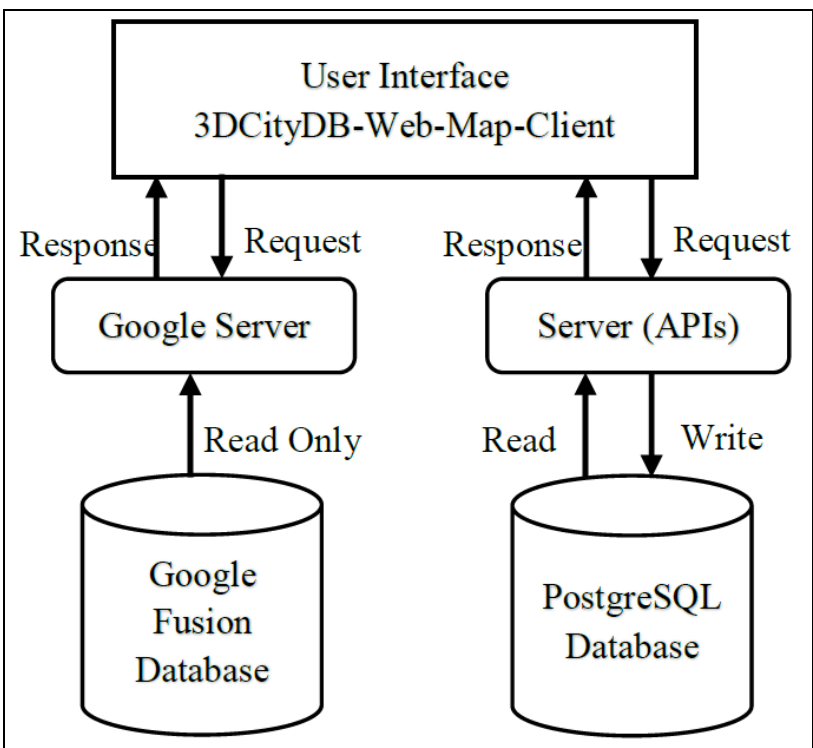

Figure 8. REST APIs server architecture, on the right, compared to the existing one, based on Google services, on the left

In this way, the user is able to control and manage the thematic data layers by using the 3DCityDB-Webmap-Client as usual, either as layers linked with a Google Fusion table URLs or with the REST APIs server URL. If the user clicks on a city object that has a thematic data URL of a Google Fusion table, then the standard functionalities are provided (read-only access). If the user clicks on a city object with thematic data URL of a REST APIs server then the user can also update the city object attributes.

\section{CONCLUSIONS}

In this article a methodology for the assessment of the energy performance of residential buildings in a test area in Vienna, namely the $12^{\text {th }}$ district Meidling, as well as some web-based $3 \mathrm{D}$ visualisation and data exploration tools were presented. They all share a semantic 3D city model as homogeneous and centralised information hub. The 3D city mode is based on the CityGML standard, although extended by means of its Energy Application Domain Extension (ADE).

With regard to the estimation of the energy performance of residential buildings, the calculation method is based on the Austrian Guideline 6 of the Austrian Institute of Construction Engineering and allows to obtain several energy-related parameters, such as the heating energy demand, the energy demand for domestic hot water production, the electricity demand, the primary energy demand and the $\mathrm{CO}_{2}$-emissions. The same parameters were then recomputed for different scenarios, in which a number of measures to refurbish the thermal hull and to increase the use of renewables were defined and computed, and finally aggregated at building block level.

The input data were mostly extracted or derived directly from the 3D city model. If this was not possible, existing parameter libraries were used. The entire $12^{\text {th }}$ district of Vienna, Meidling, was used a test site, and contains about 7400 buildings, including about 5600 residential or mixed residential buildings.

When it comes to the $3 \mathrm{D}$ visualisation and data exploration possibilities, the open nature of the Cesium-based 3DCityDBWebmap-Client has allowed to start developing extended functionalities: the "Twin Viewer"-modus, on one hand, which enables the visual comparison of different scenarios in a side by side 3D view, and the "Cesium2PSQL" data connector, on the other hand, which enables retrieval and editing of the 3D model thematic data stored in a PostgreSQL database. Both extensions provide great potential for further development in the 3D visualisation and data analysis via the 3DCityDB-WebmapClient.

The implemented tools contribute to answering some of the questions raised at the beginning of this paper, i.e. they help a) to spatially identify energy-inefficient buildings; $b$ ) to evaluate the impact of refurbishment measures in order to increase their energy efficiency, and, thanks to the bottom-up approach, c) to evaluate the energy performance of a block (or district). As a consequence, it is now easier to understand how the energy demand is going to change in the near and mid-term future.

\subsection{Outlook}

Some improvements to the methodology are already planned. Among other things, it is planned to extend the approach to non-residential buildings, and to use a finer level of detail for buildings with mixed use. Although the goal of work described in this paper was, first and foremost, the identification, development and implementation of the methodology for the determination of the energy characteristics in combination with a semantic 3D city model, a further major point is to properly calibrate the model. The most straightforward way consists for example in comparing the results with the existing Energy Performance Certificates (EPCs) of a selected number of buildings, or with real consumption data. However, at the time of writing, neither of these data sources have been made available by the City of Vienna. Nevertheless, results from analogous experiences in other cities in Europe have shown that a deviation of up to $\pm 30 \%$ between the estimated values and the EPCs can be expected (Nouvel et al. 2017). An alternative approach, in case no real data can be retrieved, would be to compare results obtained by different energy simulation tools, as proposed for example by Monien et al. (2017).

The adoption of a 3D city models as integrated information source can however greatly contribute to the reduction of the simplifying assumptions and therefore to a general increase of the overall accuracy in the estimations.

As far as the 3D visualisation and data exploration possibilities are concerned, some improvements are already planned. The next version the "Twin view"-extension will provide the possibility to dynamically load data layers via the web interface for both map frames in order to have greater flexibility in comparison to the currently hard-coded ones. It will also enable data retrieval for the city objects' underlying data sets in the right hand side map frame. On the other hand, the "Cesium2PSQL"-extension will be improved to allow for 
secured connections, user authentication, and will be extended with a fine-grained data access mechanism to give access to authorised users only, should the data for example be of privacy-related nature.

\section{ACKNOWLEDGEMENTS}

The authors gratefully acknowledge the European Commission for providing financial support during the conduct of research under the FP7-PEOPLE-2013 Marie Curie Initial Training Network "CI-NERGY" project with Grant Agreement Number 606851 .

Research work and tests regarding the Cesium-based visualisation applications were carried out partially within the IntegrCiTy project [INTEGRCITY, 2017], which is funded by the Austrian Federal Ministry for Transport, Innovation and Technology within the framework of the ENERGIE DER ZUKUNFT/JPI Urban, with support from the European Union's Horizon 2020 research and innovation programme.

As stated in section 2, some of the datasets used in this work were kindly provided by the city of Vienna specifically for the CI-NERGY project.

\section{REFERENCES}

Agugiaro, G., 2016a, Energy planning tools and CityGMLbased 3D virtual city models. Experiences from Trento (Italy). Applied Geomatics, 8/1:41-56, Springer Berlin Heidelberg.

Agugiaro, G., 2016b, First steps towards an integrated CityGML-based 3D model of Vienna. ISPRS Ann. Photogramm. Remote Sens. Spatial Inf. Sci., III-4, pp. 139146.

Agugiaro, G., 2016c, Enabling "energy-awareness" in the semantic 3D city model of Vienna. ISPRS Ann. Photogramm. Remote Sens. Spatial Inf. Sci., IV-4-W1, pp. 81-88.

Agugiaro, G., Robineau, J.L., Rodrigues, P., 2017, Project CINERGY: Towards an integrated energy urban planning system from a data modelling and system architecture point of view. ISPRS Ann. Photogramm. Remote Sens. Spatial Inf. Sci. $2^{\text {nd }}$ Int. Conf on Smart Data and Smart Cities 2017, Puebla, Mexico, 4-6 October 2017.

Bahu, J.M., Koch, A., Kremers, E., Murshed, S.M., 2013, Towards a 3D spatial urban energy modelling approach. ISPRS Ann. Photogramm. Remote Sens. Spatial Inf. Sci., II2/W1, pp. 33-41.

Benner, J., Geiger, A., Häfele, K.H., 2016, Virtual 3D City Model Support for Energy Demand Simulations on City Level - The CityGML Energy Extension. Proceedings REAL CORP Conference 2016, pp. 777-786.

Biljecki, F., Ledoux, H., Stoter, J., 2017, Generating 3D city models without elevation data. Computers, Environment and Urban Systems, 64, pp. 1-18.

Biljecki, F., Stoter, J., Ledoux, H., Zlatanova, S., Çöltekin, A., 2015, Applications of 3D city models: state of the art review. ISPRS Int. Journal of Geo-Information, 4(4), pp. 2842-2889.

Bretschneider, B., Herzog, M., Zelger, T., 2002, Multifunktionaler Stadtnukleus, Planung eines multifunktionalen Gebäudekomplexes unter Berücksichtigung energetischer Planungsfaktoren. Berichte aus Energie- und Umweltforschung, Bundesministerium für Verkehr, Innovation und Technologie.

Carrión, D., Lorenz, A., Kolbe, T.H., 2010, Estimation of the energetic rehabilitation state of buildings for the city of Berlin using a 3D City Model represented in CityGML.
ISPRS Arch. Photogramm. Remote Sens. Spatial Inf. Sci., 38(4/W15), pp. 31-35.

Kaden, R., Kolbe, T.H., 2013, City-wide total energy demand estimation of buildings using Semantic 3D city models and statistical data. ISPRS Ann. Photogramm. Remote Sens. Spatial Inf. Sci., II-2/W1, pp. 163-171.

Krüger, A., Kolbe, T.H., 2012, Building analysis for urban energy planning using key indicators on virtual 3D city models - the Energy Atlas of Berlin. ISPRS Ann. Photogramm. Remote Sens. Spatial Inf. Sci., 39(B2), pp. 145-150.

Monien, D., Strzalka, A., Koukofikis, A., Coors, V., Eicker, U., 2017, Comparison of building modelling assumptions and methods for urban scale heat demand forecasting. Future Cities and Environment, 3(1), 2.

Nouvel, R., Bahu, J.-M., Kaden, R., Kämpf, J, Cipriano, P., Lauster, M, Häfele, K.H., Munoz, E., Tournaire, O., Casper, E., 2015a, Development of the CityGML Application Domain Extension Energy for Urban Energy Simulation. Proceedings of BS2015: $14^{\text {th }}$ Conf. of Int. Building Performance Simulation Association, Hyderabad, India.

Nouvel, R., Mastrucci, A., Leopold, U., Baume, O., Coors, V., Eicker, U., 2015b, Combining GIS-based statistical and engineering urban heat consumption models: Towards a new framework for multi-scale policy support. Energy and Buildings, 107, pp. 204-212.

Nouvel, R., Schulte, C., Eicker, U., Pietruschka, D., Coors, V., 2013, CityGML-based 3D city model for energy diagnostics and urban energy policy support, IBPSA World 2013, pp. 17.

Nouvel, R., Zirak, M., Coors, V., Eicker, U., 2017, The influence of data quality on urban heating demand modeling using 3D city models. Computers, Environment and Urban Systems, 64(2017), pp. 68-80.

Romero Rodríguez, L., Duminil, E., Sánchez Ramos, J., Eicker, U., 2017, Assessment of the photovoltaic potential at urban level based on 3D city models: A case study and new methodological approach. Solar Energy, 146, pp. 264-275.

Strzalka, A., Bogdahn, J., Coors, V., Eicker, U., 2011, 3D City modeling for urban scale heating energy demand forecasting. HVAC\&R Research, 17(4), pp. 526-539.

Chaturvedi, K., Yao, Z., Kolbe, T.H., 2015, Web-based Exploration of and interaction with large and deeply structured semantic 3D city models using HTML5 and WebGL. In: Wissenschaftlich-Technische Jahrestagung der DGPF und Workshop on Laser Scanning Applications (3).

\section{REFERENCES FROM WEBSITES (30 APRIL 2017)}

3DCITYDB, http://www.3dcitydb.org 3DCITYDB-WEBMAPCLIENT, https://github.com/3dcitydb/3dcitydb-web-map CESIUM, https://cesiumjs.org/

CI-NERGY, http://www.ci-nergy.eu

ENERGY-ADE, http://en.wiki.energy.sig3d.org

INTEGRCITY, http://integrcity.epfl.ch

OGD-W, https://open.wien.gv.at

OIB, https://www.oib.or.at/en/oib-guidelines

OGC, http://www.opengeospatial.org

SC-W,

https://smartcity.wien.gv.at/site/files/2014/09/SmartCityWien_F rameworkStrategy_english_doublepage.pdf SEP-W,

https://www.wien.gv.at/stadtentwicklung/energie/pdf/sependbericht.pdf

TABULA, http://episcope.eu/iee-project/tabula/ 